\title{
ОПТИМІЗАЦІЯ МОДЕЛІ ФАКТОРІВ ПРОЦЕСУ ПРОЕКТУВАННЯ ЕЛЕКТРОННОГО ВИДАННЯ ДЛЯ ПЛАНШЕТНОГО КОМП'ЮТЕРА
}

๑ Ю. В. Ратушняк, аспірант, УАД, Львів, Україна

\section{Синтезирована оптимизированная модель множества клю- чевых Факторов, упорядоченных по важности влияния на процесс проектирования электронного издания для план- шетного компьютера.}

The synthesis of optimized model of factors that have influence on the process of designing the electronic edition for tablet computer is the actual continuation of research of the process.

\section{Постановка проблеми}

Актуальним продовженням дослідження процесу проектування електронного видання (EB) для планшетного комп'ютера (ПлК) [4] вважаємо синтез оптимізованої моделі ієрархії факторів впливу на процес проектування ЕВ для ПлК. Модифікуємо запропоновану раніше множину ключових факторів з огляду на нові експертно виявлені зв'язки між ними [6-8].

\section{Результати проведених досліджень}

Поставлене завдання вирішимо в декілька етапів:

1) за допомогою засобів теорії графів та методів системного аналізу [4] будуємо домінантну ієрархічну модель факторів впливу на процес проектування ЕВ для ПлК;

2) за допомогою методу попарного порівняння факторів (метод аналізу ієрархій), запропонованого Т. Сааті, отримуємо вектор ваг факторів, що впливають на процес проектування EB для ПлК;
3) порівнюємо результати отримані на попередніх двох етапах та синтезуємо оптимізовану модель ієрархії впливу на процес проектування ЕВ для ПлК.

Перший етап.

Нехай сукупність факторів впливу на процес проектування EВ для ПлК становить множину елементів $\mathrm{V}=\left\{v_{1}, v_{2}, \ldots, v_{n}\right\}$. 3 цієї сукупності виберемо оптимальну за важливістю та кількістю підмножину ключових факторів $\mathrm{V}_{1} \in \mathrm{V}$ (табл.).

Аналіз підмножини факторів $\mathrm{V}_{1}$ забезпечує визначення множини зв'язків між ними та подання у вигляді орієнтованого графа (рис. 1).

За допомогою початкового орієнтованого графа (рис. 1) будуємо бінарну матрицю досяжності $\mathrm{M}^{\prime}$ для множини вершин $\mathrm{V}_{1}$, формула 1.

У результаті восьми ітерацій аналізу бінарної матриці досяжності М' (рис. 2) отримуємо наступне розміщення факторів за рівнями ієрархії: перший рівень - фактор 1 (вид ЕВ / інформаційне наповнення ЕВ 
Підмножина ключових факторів V1 впливу на процес проектування електронного видання для планшетного комп'ютера

\begin{tabular}{|c|l|c|}
\hline $\begin{array}{c}\text { Номер } \\
\text { фактора, } \mathrm{i}\end{array}$ & \multicolumn{1}{|c|}{ Назва фактора } & $\begin{array}{c}\text { Мнемонічна } \\
\text { назва }\end{array}$ \\
\hline 1 & Вид ЕВ/ інформаційне наповнення ЕВ (content) & ВВ \\
\hline 2 & Візуальний дизайн ЕВ (visual design) & ВД \\
\hline 3 & Дизайн інтерфейсу EB (interface design) & ДІ \\
\hline 4 & Дизайн навігація ЕВ (navigation design) & ДН \\
\hline 5 & Зручність у використанні ЕВ (usability engineering) & ЗВ \\
\hline 6 & Інтерактивний дизайн ЕВ (interaction design) & ІД \\
\hline 7 & Інформаційна архітектура EB(information architecture) & ІА \\
\hline 8 & Технічні характеристики ПлК (industrial design) & ТХ \\
\hline
\end{tabular}

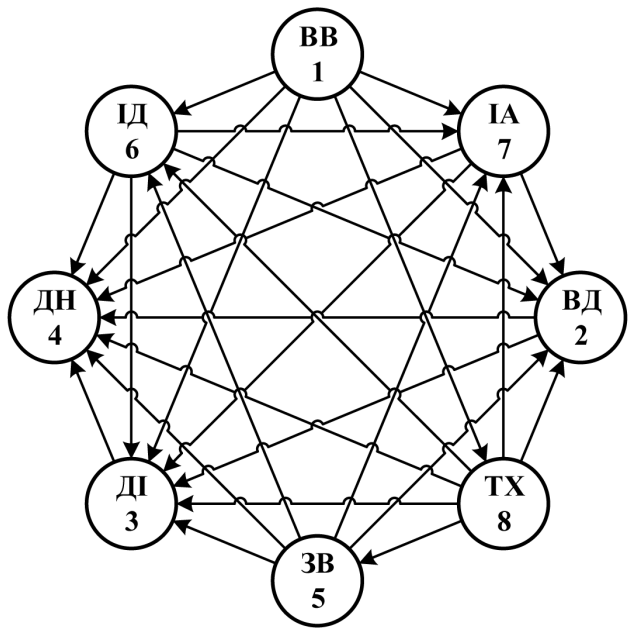

Рис. 1. Граф зв'язків між факторами впливу на процес проектування електронного видання для планшетного комп'ютера

$$
\begin{aligned}
& \text { ВВ ВД ДІ ДН ЗВ ІД ІА ТХ }
\end{aligned}
$$

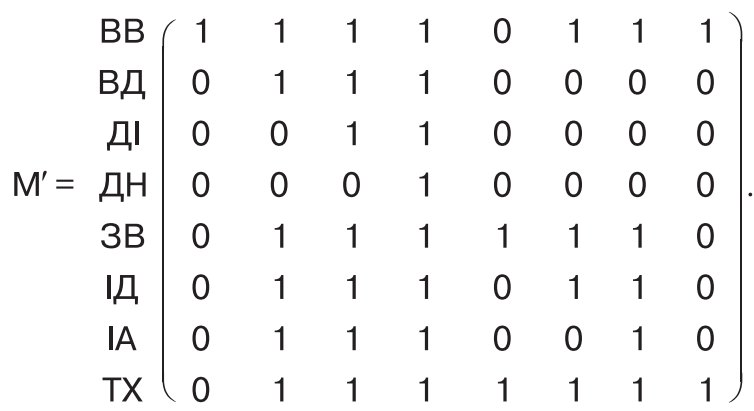

(content)), другий рівень - фактор 8 (технічні характеристики ПлК (industrial design)), третій рівень - фактор 5 (зручність у використанні EB (usability engi- neering)), четвертий рівень фактор 6 (інтерактивний дизайн EB (interaction design)), п'ятий рівень - фактор 7 (інформаційна архітектура EB (infor- 
mation architecture)), шостий рівень - фактор 2 (візуальний дизайн EB (visual design)), сьомий рівень - фактор 3 (дизайн

інтерфейсу EB (interface design)), восьмий рівень - фактор 4 (дизайн навігація EB (navigation design)).

a)

\begin{tabular}{|c|c|c|c|}
\hline $\mathbf{i}$ & $\mathrm{L}\left(\mathrm{c}_{\mathrm{i}}\right)$ & $\mathrm{P}\left(\mathrm{c}_{\mathrm{i}}\right)$ & $\mathrm{L}\left(\mathrm{c}_{\mathrm{i}}\right) \cup \mathrm{P}\left(\mathrm{c}_{\mathrm{i}}\right)$ \\
\hline 1 & $1,2,3,4,6,7,8$ & 1 & 1 \\
\hline 2 & $2,3,4$ & $1,2,5,6,7,8$ & 2 \\
\hline 3 & 3,4 & $1,2,3,5,6,7,8$ & 3 \\
\hline 4 & 4 & $1,2,3,4,5,6,7,8$ & 4 \\
\hline 5 & $2,3,4,5,6,7$ & 5,8 & 5 \\
\hline 6 & $2,3,4,6,7$ & $1,5,6,8$ & 6 \\
\hline 7 & $2,3,4,7$ & $1,5,6,7,8$ & 7 \\
\hline 8 & $2,3,4,5,6,7,8$ & 1,8 & 8 \\
\hline
\end{tabular}

б)

\begin{tabular}{|c|c|c|c|}
\hline $\mathbf{i}$ & $\mathrm{L}\left(\mathrm{c}_{\mathrm{i}}\right)$ & $\mathrm{P}\left(\mathrm{c}_{\mathrm{i}}\right)$ & $\mathrm{L}\left(\mathrm{c}_{\mathrm{i}}\right) \cup \mathrm{P}\left(\mathrm{c}_{\mathrm{i}}\right)$ \\
\hline 2 & $2,3,4$ & $2,5,6,7,8$ & 2 \\
\hline 3 & 3,4 & $2,3,5,6,7,8$ & 3 \\
\hline 4 & 4 & $2,3,4,5,6,7,8$ & 4 \\
\hline 5 & $2,3,4,5,6,7$ & 5,8 & 5 \\
\hline 6 & $2,3,4,6,7$ & $5,6,8$ & 6 \\
\hline 7 & $2,3,4,7$ & $5,6,7,8$ & 7 \\
\hline 8 & $2,3,4,5,6,7,8$ & 8 & 8 \\
\hline
\end{tabular}

в)

\begin{tabular}{|c|c|c|c|}
\hline $\mathbf{i}$ & $\mathrm{L}\left(\mathrm{c}_{\mathrm{i}}\right)$ & $\mathrm{P}\left(\mathrm{c}_{\mathrm{i}}\right)$ & $\mathrm{L}\left(\mathrm{c}_{\mathrm{i}}\right) \cup \mathrm{P}\left(\mathrm{c}_{\mathrm{i}}\right)$ \\
\hline 2 & $2,3,4$ & $2,5,6,7$ & 2 \\
\hline 3 & 3,4 & $2,3,5,6,7$ & 3 \\
\hline 4 & 4 & $2,3,4,5,6,7$ & 4 \\
\hline 5 & $2,3,4,5,6,7$ & 5 & 5 \\
\hline 6 & $2,3,4,6,7$ & 5,6 & 6 \\
\hline 7 & $2,3,4,7$ & $5,6,7$ & 7 \\
\hline
\end{tabular}

г)

\begin{tabular}{|c|c|c|c|}
\hline $\mathbf{i}$ & $\mathrm{L}\left(\mathrm{c}_{\mathrm{i}}\right)$ & $\mathrm{P}\left(\mathrm{c}_{\mathrm{i}}\right)$ & $\mathrm{L}\left(\mathrm{c}_{\mathrm{i}}\right) \cup \mathrm{P}\left(\mathrm{c}_{\mathrm{i}}\right)$ \\
\hline 2 & $2,3,4$ & $2,6,7$ & 2 \\
\hline 3 & 3,4 & $2,3,6,7$ & 3 \\
\hline 4 & 4 & $2,3,4,6,7$ & 4 \\
\hline 6 & $2,3,4,6,7$ & 6 & 6 \\
\hline 7 & $2,3,4,7$ & 6,7 & 7 \\
\hline
\end{tabular}

r)

\begin{tabular}{|c|c|c|c|}
\hline $\mathbf{i}$ & $\mathrm{L}\left(\mathrm{c}_{\mathrm{i}}\right)$ & $\mathrm{P}\left(\mathrm{c}_{\mathrm{i}}\right)$ & $\mathrm{L}\left(\mathrm{c}_{\mathrm{i}}\right) \cup \mathrm{P}\left(\mathrm{c}_{\mathrm{i}}\right)$ \\
\hline 2 & $2,3,4$ & 2,7 & 2 \\
\hline 3 & 3,4 & $2,3,7$ & 3 \\
\hline 4 & 4 & $2,3,4,7$ & 4 \\
\hline 7 & $2,3,4,7$ & 7 & 7 \\
\hline
\end{tabular}

д)

\begin{tabular}{|c|c|c|c|}
\hline $\mathbf{i}$ & $\mathrm{L}\left(\mathrm{c}_{\mathrm{i}}\right)$ & $\mathrm{P}\left(\mathrm{c}_{\mathrm{i}}\right)$ & $\mathrm{L}\left(\mathrm{c}_{\mathrm{i}}\right) \cup \mathrm{P}\left(\mathrm{c}_{\mathrm{i}}\right)$ \\
2 & $2,3,4$ & 2 & 2 \\
3 & 3,4 & 2,3 & 3 \\
4 & 4 & $2,3,4$ & 4 \\
\hline
\end{tabular}

e)

\begin{tabular}{|c|c|c|c|}
\hline $\mathrm{i}$ & $\mathrm{L}\left(\mathrm{c}_{\mathrm{i}}\right)$ & $\mathrm{P}\left(\mathrm{c}_{\mathrm{i}}\right)$ & $\mathrm{L}\left(\mathrm{c}_{\mathrm{i}}\right) \cup \mathrm{P}\left(\mathrm{c}_{\mathrm{i}}\right)$ \\
\hline 3 & 3,4 & 3 & 3 \\
\hline 4 & 4 & 3,4 & 4 \\
\hline
\end{tabular}

c)

\begin{tabular}{|c|c|c|c|}
\hline $\mathrm{i}$ & $\mathrm{L}\left(\mathrm{c}_{\mathrm{i}}\right)$ & $\mathrm{P}\left(\mathrm{c}_{\mathrm{i}}\right)$ & $\mathrm{L}\left(\mathrm{c}_{\mathrm{i}}\right) \cup \mathrm{P}\left(\mathrm{c}_{\mathrm{i}}\right)$ \\
\hline 4 & 4 & 4 & 4 \\
\hline
\end{tabular}

Рис. 2. Ітерації аналізу бінарної матриці досяжності М' (a) - $)$ : перша восьма), де $L\left(c_{i}\right)$ - досягнуті вершини, $\mathrm{P}\left(\mathrm{c}_{\mathrm{i}}\right)$ - вершини-попередниці 
Результатом виконаних дій над елементами початкового орієнтованого графа (рис. 1) стала домінантна ієрархічно впорядкована модель (рис. 3) ієрархії ваг факторів впливу на процес проектування ЕВ для ПлК.

Другий етап.

Поставлене завдання розв'яжемо методом попарного порівняння факторів, запропонованого Т. Сааті. На основі описаних теоретичних викладок [1-3, 5], вирішимо задачу багатофакторної оптимізації під час виконання методу лінійного згортання факторів.
Матриця попарних порівнянь $\mathrm{A}$ для підмножини факторів $\mathrm{V}_{1}$, формула 2.

Решту необхідних обрахунків згідно методу попарних порівнянь проводимо в програмі для роботи 3 таблицями Microsoft Excel (рис. 4).

У результаті дослідження отримано вектор ваг факторів впливу на процес проектування ЕВ для ПлК:

$$
\begin{array}{r}
\overline{\mathrm{w}}=(0,327 ; 0,050 ; 0,034 ; 0,024 ; \\
0,157 ; 0,108 ; 0,073 ; 0,227)^{\top} .
\end{array}
$$

Третій етап.

Щоб порівняти результати, отримані на двох попередніх

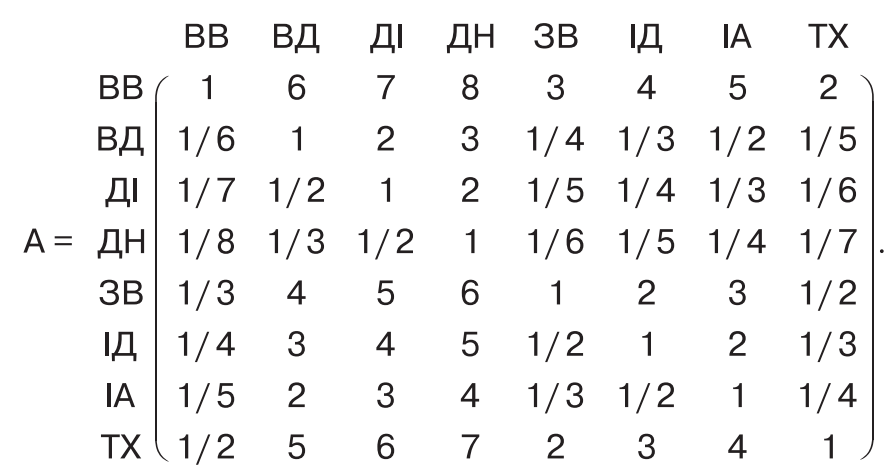

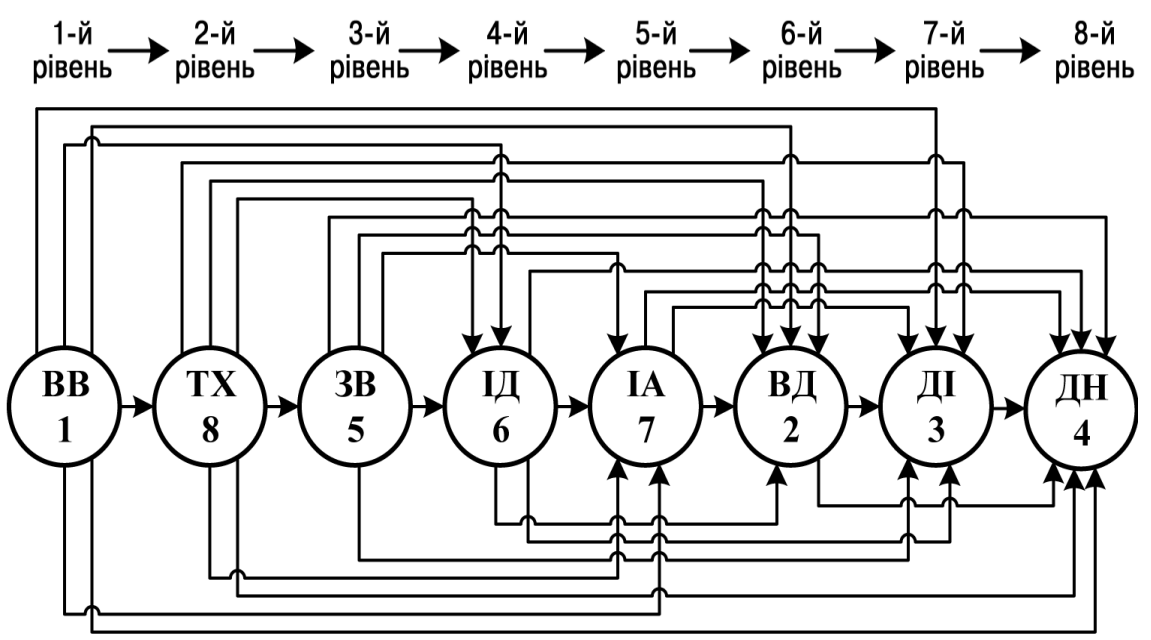

Рис. 3. Модель ієрархії ваг факторів впливу на процес проектування електронного видання для планшетного комп'ютера 


\begin{tabular}{|c|c|c|c|c|c|c|c|c|}
\hline \multirow{2}{*}{$\begin{array}{c}\text { Метод } \\
\text { попарних } \\
\text { порівнянь }\end{array}$} & \multicolumn{8}{|c|}{ Суми елементів стовпців матриці попарних порівнянь } \\
\hline & 2,718 & 21,833 & 28,500 & 36,000 & 7,450 & 11,283 & 16,083 & 4,593 \\
\hline \multicolumn{9}{|c|}{ Нормалізована матриця } \\
\hline Критерії & BB & ВД & ДI & ДН & 3B & ІІД & IA & $\mathbf{T X}$ \\
\hline BB & 0,368 & 0,275 & 0,246 & 0,222 & 0,403 & 0,355 & 0,311 & 0,435 \\
\hline ВД & 0,061 & 0,046 & 0,070 & 0,083 & 0,034 & 0,030 & 0,031 & 0,044 \\
\hline ДІ & 0,053 & 0,023 & 0,035 & 0,056 & 0,027 & 0,022 & 0,021 & 0,036 \\
\hline ДН & 0,046 & 0,015 & 0,018 & 0,028 & 0,022 & 0,018 & 0,016 & 0,031 \\
\hline 3B & 0,123 & 0,183 & 0,175 & 0,167 & 0,134 & 0,177 & 0,187 & 0,109 \\
\hline ІД & 0,092 & 0,137 & 0,140 & 0,139 & 0,067 & 0,089 & 0,124 & 0,073 \\
\hline IA & 0,074 & 0,092 & 0,105 & 0,111 & 0,045 & 0,044 & 0,062 & 0,054 \\
\hline \multirow[t]{2}{*}{ TX } & 0,184 & 0,229 & 0,211 & 0,194 & 0,268 & 0,266 & 0,249 & 0,218 \\
\hline & \multicolumn{2}{|c|}{$\mathrm{k}_{\max }=8,423$} & & \multicolumn{2}{|c|}{$\mathrm{CR}=0,041$} & & & \\
\hline & - & - & 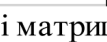 & (n) & Пс & $\mathrm{Hb}$ & in & \\
\hline
\end{tabular}

Рис. 4. Частина інтерфейсу програми Microsoft Excel, в якій були виконані всі обрахунки по методу попарних порівнянь

етапах, потрібно привести їх значення до одного виду. Для одержання вагових значень факторів ієрархічної моделі рис. 3 присвоїмо їм умовні числові значення, що відображають вагу фактора в загальній схемі. Отож, нехай восьмому рівню ієрархії відповідатиме число 10, а значення кожного вищого рівня утворюватимуть послідовність Фібоначчі. Результатом таких припущень стане вектор

$\overline{\mathrm{I}}=(340 ; 30 ; 20 ; 10 ; 130 ; 80 ; 50 ; 210)$.
Вектор ваг факторів, отриманий на другому етапі помножимо на деякий коефіцієнт $z=1000$. Гістограма порівняння результатів представлена на рис. 5.

Оскільки ваги факторів, отримані різними методами, близькі за значенням, на їх основі синтезували оптимізовану модель ієрархії факторів впливу на процес проектування ЕВ для ПлК (рис. 6). Вирішення задачі побудови такої моделі забезпечує уточнення та формалізацію процесу проектування ЕВ для ПлК.



Рис. 5. Гістограма вагових значень факторів отриманих з допомогою різних методик: I - засобів теорії графів і методів системного аналізу; II - метод попарних порівнянь 
Іерархія факторів впливу на процес проектування ЕВ для ПлК

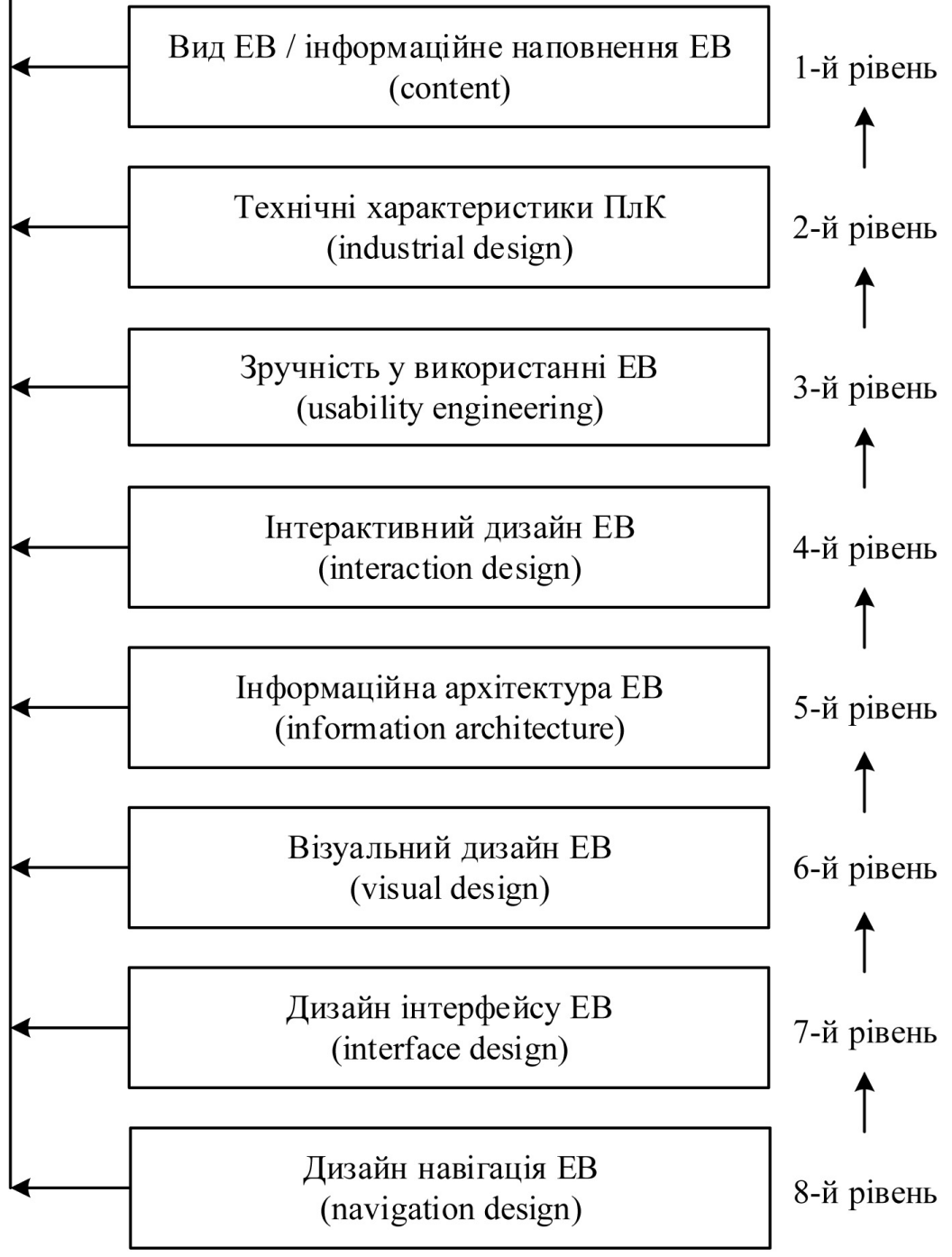

Рис. 6. Оптимізована модель ієрархії факторів впливу на процес проектування електронного видання для планшетного комп'ютера

\section{Висновки}

Таким чином, у результаті дослідження отримано оптимізовану модель ієрархії впливу виокремлених факторів на процес проектування ЕВ для
ПлК. Вона стане основою для багатокритеріального вибору альтернативних варіантів формування ЕВ на основі нечіткої переваги альтернатив. 
1. Бартіш М. Я. Дослідження операцій. Частина 3. Ухвалення рішень і теорія ігор : підручник / М. Я. Бартіш, І. М. Дудзяний. - Львів : Видавничий центр ЛнУ імені Івана Франка, 2009. - 278 с. 2. Сявавко М. С. Інтелектуалізована інформаційна система «Нечіткий експерт» / М. С. Сявавко Львів : Видавничий центр ЛнУ імені Івана Франка, 2007. - 320 с. 3. Ратушняк Ю. В. Синтез моделі критеріїв вибору мобільної апаратно-програмної платформи в процесі проектування електронного видання для планшетного комп'ютера / Ю. В. Ратушняк // Поліграфія і видавнича справа. Науковотехнічний збірник. - 2012. - № 3(59). - С. 78-104. 4. Ратушняк Ю. В. Модель факторів процесу проектування електронного видання для планшетного комп'ютера / Ю. В. Ратушняк, В. М. Сеньківський // Поліграфія і видавнича справа. Науково-технічний збірник. - 2011. - № 4(56). - С. 136-144. 5. Хемди А. Таха Введение в исследование операций, 7-е издание / А. Таха Хемди; [пер. с англ.]. - М. : Издательский дом «Вильямс», 2007. - 912 с. 6. Garrett Jesse James The Elements of user experience : User-Centered Design for the Web and Beyond (2nd Edition) / Jesse James Garrett. - New Riders. -2010 . - 192 p. 7. Hartson Rex The UX Book : Process and guidelines for ensuring a quality user experience / Rex Hartson, Pardha Pyla. - Morgan Kaufmann, 2012. - 968 p. 8. Saffer Dan Designing for interaction : Creating innovative applications and devices (2nd edition) / Dan Saffer. - New Riders, 2009. - 240 p.

1. Bartish M. la. Doslidzhennia operatsii. Chastyna 3. Ukhvalennia rishen i teoriia ihor : pidruchnyk / M. la. Bartish, I. M. Dudzianyi. - Lviv : Vydavnychyi tsentr LNU imeni Ivana Franka, 2009. - 278 s. 2. Siavavko M. S. Intelektualizovana informatsiina systema «Nechitkyi ekspert» / M. S. Siavavko Lviv : Vydavnychyi tsentr LNU imeni Ivana Franka, 2007. - 320 s. 3. Ratushniak lu. V. Syntez modeli kryteriiv vyboru mobilnoi aparatno-prohramnoi platformy $v$ protsesi proektuvannia elektronnoho vydannia dlia planshetnoho komp'iutera / lu. V. Ratushniak // Polihrafiia i vydavnycha sprava. Naukovo-tekhnichnyi zbirnyk. - 2012. - № 3(59). - S. 78-104. 4. Ratushniak lu. V. Model faktoriv protsesu proektuvannia elektronnoho vydannia dlia planshetnoho komp'iutera / lu. V. Ratushniak, V. M. Senkivskyi // Polihrafiia i vydavnycha sprava. Naukovotekhnichnyi zbirnyk. - 2011. - № 4(56). - S. 136-144. 5. Hemdi A. Taha Vvedenie $v$ issledovanie operacij, 7-e izdanie / A. Taha Hemdi; [per. s angl.]. M. : Izdatel'skij dom «Vil'jams», 2007. - 912 s. 6. Garrett Jesse James The Elements of user experience : User-Centered Design for the Web and Beyond (2nd Edition) / Jesse James Garrett. - New Riders. - 2010. - 192 p. 7. Hartson Rex The UX Book : Process and guidelines for ensuring a quality user experience / Rex Hartson, Pardha Pyla. - Morgan Kaufmann, 2012. - 968 p. 8. Saffer Dan Designing for interaction : Creating innovative applications and devices (2nd edition) / Dan Saffer. - New Riders, 2009. - 240 p.

Рецензент - О. В. Мельников, к.т.Н., УАД

Надійшла до редакції 22.12.12 